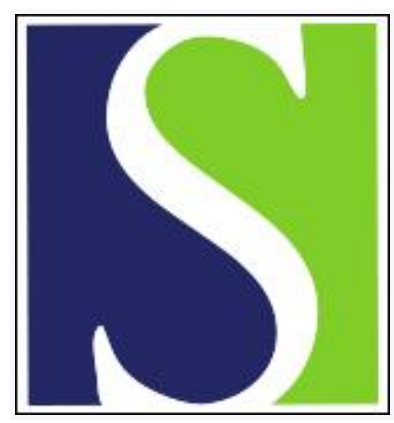

Scand J Work Environ Health 2010;36(6):509-513

https://doi.org/10.5271/sjweh.3072

Published online: 22 Jun 2010, Issue date: Nov 2010

White fingers, cold environment, and vibration - exposure among Swedish construction workers

by Burström L, Järvholm B, Nilsson T, Wahlström J

Affiliation: Department of Public Health \& Clinical Medicine, Occupational and Environmental Medicine, Umeå University, SE-901 87 Umeå, Sweden. lage.burstrom@envmed.umu.se

Refers to the following texts of the Journal: 1986;12(4):289-292 2006;32(4):270-275

The following articles refer to this text: 2019;45(1):63-72;

2023;49(2):156-163

Key terms: arm; climate; cold; construction; construction worker; exposure; hand; hand-arm vibration; HAV; occupation; raynaud phenomenon; smoking; snuff; Sweden; vibration; white finger; worker

This article in PubMed: www.ncbi.nlm.nih.gov/pubmed/20567796 


\title{
White fingers, cold environment, and vibration - exposure among Swedish construction workers
}

\author{
by Lage Burström, PhD, ${ }^{1}$ Bengt Järvholm, MD, ${ }^{1,2}$ Tohr Nilsson, MD,1, 3 Jens Wahlström, PhD ${ }^{2}$
}

\begin{abstract}
Burström L, Järvholm B, Nilsson T, Wahlström J. White fingers, cold environment, and vibration - exposure among Swedish construction workers. Scand J Work Environ \& Health. 2010;36(6):509-513.

Objectives The aim of this study was to examine the association between white fingers, cold environment, and exposure to hand-arm vibration (HAV). The hypothesis was that working in cold climate increases the risk of white fingers.
\end{abstract}

Methods The occurrence of white fingers was investigated as a cross-sectional study in a cohort of Swedish male construction workers ( $\mathrm{N}=134$ 757). Exposure to HAV was based on a job-exposure matrix. Living in the north or south of Sweden was, in a subgroup of the cohort, used as an indicator of the exposure to cold environment (ie, living in the north meant a higher exposure to cold climate). The analyses were adjusted for age and use of nicotine products (smoking and snuff).

Results HAV-exposed workers living in a colder climate had a higher risk for white fingers than those living in a warmer climate [odds ratio (OR) 1.71, 95\% confidence interval $(95 \% \mathrm{CI}) 1.42-2.06$ ]. As expected, we found that HAV-exposed workers had an increased risk compared to controls (OR 2.02, 95\% CI 1.75-2.34). The risk for white fingers increased with increased level of exposure to HAV and also age.

Conclusions Cold environment increases the risk for white fingers in workers occupationally exposed to HAV. The results underscore the need to keep exposure to HAV at workplaces as low as possible especially in cold climate.

Key terms climate; hand-arm vibration; HAV; occupation; raynaud's phenomenon; smoking; snuff.

Raynaud's phenomenon denotes an episodic vasospasm of the peripheral vessels, causing discoloration of the fingers, known as white fingers, and occasionally the toes, ears, and nose. It comprises both primary Raynaud's, where the phenomenon is idiopathic, and secondary Raynaud's, where it is caused by some other instigating factor. Occupational exposure to hand-arm vibration (HAV) has been associated with a secondary form of Raynaud's localized to the fingers and thereby known as vibration-induced white finger disease (VWF).

The association between VWF and occupations involving work with vibrating tools has clearly been established in epidemiological studies (1), but the association between VWF and cold climate have been sparsely investigated. Studies of HAV-exposed workers in tropical or subtropical areas have shown no, or very small prevalence of WF (2-4) leading the authors to conclude that the absence of symptoms could be due to the warm climate. A study carried by Yu et al (5) is the only one, as far as we know, where workers in both cold and warm climate have been studied on the same occasion. They found that the prevalence of VWF was higher in the north part of China compared with the south and midwest. However, the study lacked information about the influence of differences in the exposure of vibration as well as confounding factors for WF such as age and use of nicotine.

This study was designed to further examine the influence on working in cold climate on the risk of WF among HAV-exposed workers. We examined the risk among construction workers who reported the occurrence of WF, while the exposure to HAV was estimated through a job-exposure matrix. In this study, we adjusted for age and the use of nicotine.

1 Department of Public Health \& Clinical Medicine, Occupational and Environmental Medicine, Umeå University, Umeå, Sweden.

2 Department of Occupational and Environmental Medicine, University Hospital of Northern Sweden, Umeå, Sweden.

3 Department of Occupational and Environmental Medicine, Sundsvall Hospital, Sundsvall, SE-851 86 Sweden.

Correspondence to: Dr L Burström, Department of Public Health \& Clinical Medicine, Occupational and Environmental Medicine, Umeå University, SE-901 87 Umeå, Sweden. [E-mail: lage.burstrom@envmed.umu.se] 


\section{Methods}

The cohort consisted of workers in the Swedish construction industry that participated in health examinations on a regular basis (at intervals of 2-3 years), from the late 1960s until 1993, in a nationwide occupational health project. The workers were invited at intervals of $2-5$ years (6). Although the program was voluntary, at least $80 \%$ of eligible workers participated (7). During the health examination, the workers also answered a questionnaire about their working conditions and health status. During the period 1971-1974, the experience of WF was ascertained with the following question "Do your fingers become white and cold if they are exposed to wet or are chilled? No/Yes". Data (including occupational titles and smoking habits as well as use of snuff) from the health examinations and questionnaires were registered in a database (7).

A job-exposure matrix was developed to assess exposure to HAV. The exposure assessment was based on a survey conducted in the mid-1970s (8). Each occupation was studied at visits to approximately five worksites in different geographical regions of Sweden, but as many as 15 studies were performed when five worksites were judged not to provide enough information of the relevant exposures. The daily exposure to different agents in the work environment was graded on a $0-5$ scale by occupational hygienists and physicians. Level 3 corresponded to the hygienic threshold value at the time of the study. When no such limits were applicable, as in the case of HAV exposure, level 3 corresponded to an exposure that - at that time -was considered to be "acceptable". The assessments of HAV were made for each of the 212 codes used to describe each individual's occupation.

Between 1971-1974, 138394 workers were included in the cohort. From this group, females $(\mathrm{N}=3435)$ and subjects $>67$ years of age at the time of examination $(\mathrm{N}=202)$ were excluded. The resulting cohort consisted of 134757 men. The group exposed to HAV included 19251 males (14.3\%). All office workers in the cohort $(\mathrm{N}=3350)$ reported no exposure to HAV and were selected as the reference group. The use of nicotine products included smoking and snuff habits at the time of the health examination. When information on smoking or snuff use was not available from the time of the first examination, information from a later visit was used. In the analyses, the use of nicotine was classified as "yes" or "no". Ex-smokers were classified as "no".

The health examinations were conducted in 12 different geographic regions. Contrast of cold environment was accomplished by choosing the most northern and southern regions. The most northern region (Luleå) included 12 643 workers of which 1791 (14.2\%) were exposed to HAV. The most southern region (Malmö) consisted of
20881 subjects of which 3064 (14.7\%) were exposed to HAV. Odds ratios (OR) were calculated by ordinal and multinomial logistic regression, using the reference group as a control. The etiologic fractions was calculated as (RR-1)/RR, where RR is the adjusted OR for each category in comparison. All statistical analyses were performed with the statistical software package SPSS, version 16.0 (SPSS Inc, Chicago, Illinois, USA). The Regional Board of Ethical Vetting for medical research in Umeå, Sweden, approved the study (2009-88M).

\section{Results}

The prevalence of WF among those exposed to HAV was $13.4 \%$ and $8.4 \%$ among the referents. The risk for WF increased with age among both HAV-exposed workers and referents (table 1). In workers exposed to HAV, the risk for WF was higher among nicotine users compared to non-users [OR 1.56, 95\% confidence interval (95\% CI) 1.43-1.71].

There was an increased risk for WF among HAVexposed workers compared to the non-exposed reference group and also according to actual load (table 2). The risk was more pronounced for the two highest categories of vibration exposure (levels 4 and 5). The adjusted OR $\left(\mathrm{OR}_{\mathrm{adj}}\right)$ for WF for those exposed to HAV at the highest levels (4 and 5) compared to those exposed at the lowest levels (1, 2 and 3 ) was 3.53 (95\% CI 3.22-3.88).

The risk for reported WF was higher in workers living in the north compared to those living in the south (OR adjusted for age, nicotine and level of exposure: $1.51,95 \%$ CI $1.24-1.84)$. Furthermore, an analysis revealed that, within the reference group, there was no difference between the northern and southern region in the risk for WF $\left(\mathrm{OR}_{\mathrm{adj}} 1.02,95 \% \mathrm{CI} 0.59-1.76\right)$.

\section{Discussion}

The results of our study support the hypothesis that low outdoor temperatures increase the prevalence of selfreported WF among workers exposed to HAV, which is in agreement with earlier studies $(1,3-5)$. The average annual temperature was about $0^{\circ} \mathrm{C}$ in the northern region compared to $8^{\circ} \mathrm{C}$ in the southern region during the actual time period (9). The result shows that this modest difference in the mean temperature was associated with a significant difference in the subjective reported occurrence of WF.

It is a well-known fact that WF episodes are manifested or occur when the temperature is low, because low temperature significantly influences peripheral blood 
Table 1. Odds ratios (OR) and $95 \%$ confidence intervals $(95 \% \mathrm{Cl})$ for the prevalence of white finger (WF) by age and use of nicotine products for those exposed to hand-arm vibration (HAV) and the reference group, crude analyses and adjusted $0 R\left(O R_{a d j}\right)$.

\begin{tabular}{|c|c|c|c|c|c|c|c|c|c|c|}
\hline & \multicolumn{5}{|c|}{ Referents } & \multicolumn{5}{|c|}{ HAV-exposed } \\
\hline & N & $\mathrm{OR}$ & $95 \% \mathrm{Cl}$ & $\mathrm{OR}_{\mathrm{adj}}$ & $95 \% \mathrm{Cl}$ & N & $\mathrm{OR}$ & $95 \% \mathrm{Cl}$ & $O \mathrm{R}_{\mathrm{adj}}$ & $95 \% \mathrm{Cl}$ \\
\hline \multicolumn{11}{|l|}{ Age a } \\
\hline$\leq 29$ years & 564 & 1.00 & .. & 1.00 & .. & 4019 & 1.00 & .. & 1.00 & .. \\
\hline 30-39 years & 953 & 1.04 & $0.64-1.67$ & 1.07 & $0.66-1.72$ & 4205 & 1.21 & $1.05-1.39$ & 1.24 & $1.07-1.43$ \\
\hline 40-49 years & 919 & 1.31 & $0.83-2.09$ & 1.37 & $0.86-2.19$ & 4042 & 1.64 & $1.43-1.88$ & 1.71 & $1.49-1.97$ \\
\hline 50-59 years & 687 & 1.83 & $1.15-2.91$ & 1.90 & $1.29-3.02$ & 4838 & 1.91 & $1.67-2.17$ & 1.98 & $1.74-2.26$ \\
\hline$\geq 60$ years & 227 & 1.85 & $1.02-3.36$ & 1.95 & $1.07-3.54$ & 2147 & 1.86 & $1.59-2.17$ & 1.94 & $1.66-2.28$ \\
\hline \multicolumn{11}{|l|}{ Nicotine ${ }^{a}$} \\
\hline Non-user & 1824 & 1.00 & .. & . & .. & 6913 & 1.89 & $1.53-2.34$ & 1.83 & $1.49-2.27$ \\
\hline User & 1526 & 1.26 & $0.96-1.67$ & 1.33 & $1.01-1.75$ & 12338 & 2.86 & $2.33-3.50$ & 2.88 & $2.35-3.53$ \\
\hline
\end{tabular}

a The OR for age were adjusted for nicotine and the OR for nicotine were adjusted for age.

circulation $(10,11)$. One reason for our finding could be that the symptoms are more easily provoked in cold climate (ie, if the HAV-exposed workers living in the south had lived in the north they should have reported WF to the same extent). Another hypothesis could be that the decrease of the blood circulation in the fingers, due to work in cold climate, possibly influence the mechanisms of the vibration effects and in this way accelerates the risk of VWF (12). The finding of similar prevalence of $\mathrm{WF}$ among the referents $(\mathrm{OR}=1.02)$ somewhat speaks in favor of the latter hypothesis. However, a reason for the insignificant finding among the reference group could be that the office workers are less affected by outdoor temperature.

Nicotine, as with cold, constricts the peripheral blood vessels, and we found WF to be more prevalent among HAV-exposed users of nicotine products, in line with previous findings (13-15). Use of nicotine products in combination with HAV showed a high risk of WF. It is not clear whether use of nicotine products interact with the same mechanism as HAV in causing WF or if they only enhance the reported symptoms (16).

Moreover, the result shows that the OR for WF increases with age of the workers. For the reference group, this influence is significant for those $>50$ years of age. For HAV-exposed workers, this influence could be noticed from 30 years of age onwards, but in this study it is not possible to separate the cumulative vibration exposure from age.

The preventive etiologic fraction estimates suggest that elimination of the use of nicotine products would result in a $24 \%$ reduction in WF among HAV-exposed workers and elimination of HAV exposure would reduce the occurrence by $51 \%$ in this group. An increase of the mean temperature of about $8^{\circ} \mathrm{C}$ would result in a $28 \%$ reduction in WF among the HAV-exposed workers.

The strength of this cross-sectional study was its use of a large cohort and internal control group.
Table 2. Odds ratios (OR) and $95 \%$ confidence intervals $(95 \% \mathrm{Cl})$ for white fingers (WF) among workers exposed to hand-arm vibration (HAV), exposed to HAV at different levels, and in the different geographic locations compared to referents $(N=3350,0 R 1.00)$ : crude analyses and adjusted for age and use of nicotine $\left(0 R_{a d j}\right)$.

\begin{tabular}{lccccc}
\hline & \multicolumn{5}{c}{ HAV-exposed } \\
\cline { 2 - 6 } & $\mathrm{N}$ & $\mathrm{OR}$ & $95 \% \mathrm{Cl}$ & $\mathrm{OR}_{\text {adj }}$ & $95 \% \mathrm{Cl}$ \\
\cline { 2 - 6 } Total & 19251 & 2.24 & $1.94-2.58$ & 2.02 & $1.75-2.34$ \\
HAV level & & & & & \\
Level 1 & 5747 & 1.73 & $1.47-2.03$ & 1.41 & $1.23-1.62$ \\
Level 2 & 9925 & 1.63 & $1.40-1.90$ & 1.49 & $1.28-1.74$ \\
Level 3 & 557 & 1.69 & $1.24-2.29$ & 1.47 & $1.08-2.00$ \\
Level 4 & 1868 & 9.12 & $7.72-10.77$ & 8.12 & $6.87-9.60$ \\
Level 5 & 1154 & 2.68 & $2.17-3.31$ & 2.29 & $1.86-2.83$ \\
Geographic location & & & & \\
North & 1791 & 2.29 & $1.89-2.78$ & 1.99 & $1.63-2.43$ \\
South & 3064 & 1.31 & $1.09-1.58$ & 1.18 & $0.97-1.43$ \\
\hline
\end{tabular}

Furthermore, all the participants answered the same questionnaire about their working conditions and health status. However, the prevalence of WF has been estimated from the questionnaire, and this self-reported prevalence has not been verified by medical investigations and could, therefore, include both primary and secondary Raynaud's phenomenon. Moreover, the used question is not specifically related to primary or secondary Raynaud's phenomenon and could have generated false positive responses.

In the analyses, workers $>67$ years of age were excluded since this was the official retirement age in Sweden at that time.

The job-exposure matrix was based on detailed exposure estimations from the mid-1970s. This is a strength of the study, although no formal validation had been made using measurements of the vibration expo- 
sure or daily exposure time. For instance, the higher OR for reported WF among the HAV-exposed at level 4 (eg, rock workers) compared to level 5 (eg, concrete workers) could be due to misclassification. The opposite classification perhaps would have been more appropriate. However, it is difficult to quantify the 0-5-point scale for the grading of HAV exposure. Workers classified in category 3 (ie, acceptable exposure) were, for instance, concrete workers who used hand-held grinders for surface finishing of concrete walls and preparatory workers (foundation laying) using vibrating plate compactors and grinders equipped with cutting wheels. By using information from conducted measurements (17) on different types of hand-held tools, it seems reasonable to assume that workers categorized at level 3 have been exposed to a daily equivalent acceleration for eight hours $[\mathrm{A}(8)]$ between $3-4 \mathrm{~m} / \mathrm{s}^{2}$. These accelerations are above the action level $\left(2.5 \mathrm{~m} / \mathrm{s}^{2}\right)$ but below the exposure limit value $\left(5.0 \mathrm{~m} / \mathrm{s}^{2}\right)$ established in the European vibration directive (18). Some of the occupations, such as those working with asphalt, could be regarded as seasonal work and differences in the total exposure time have not being taken into account in the analyses. It is also reasonable to assume that some of the workers have changed work and previously been exposed to HAV as well as some of the workers in the reference group who could also previously have been exposed to HAV. Furthermore, the exposure matrix is based on job titles only, and these titles have not taken the individual variation of exposure into account.

The effect of temperature has only been estimated by outdoor mean temperature of the region at time of the health examination. There is no reason to assume that the amount of outdoor work differ between the north and south part of Sweden but there could, however, have been differences in the use of protective clothing. Some workers may also have moved from, and previously been exposed to, higher/lower mean temperatures. All such missclassification would mainly be random and cause underestimation of true associations. It is not known whether the risk is best described by differences in mean temperature or by the occurrence of episodes with very low temperature. In the northern region, there are regularly episodes with temperatures below $-20^{\circ} \mathrm{C}$ during the winter.

The possibility of a healthy-worker effect in construction work must be considered. A tendency towards this could be seen from the finding that the OR for WF is lower for those $>60$ years than those aged $50-59$ years among HAV-exposed workers but not the referents.

Female workers were excluded because very few women were exposed to HAV $(\mathrm{N}=14)$. Compared to the male workers, the female workers showed a risk of $\mathrm{WF}\left(\mathrm{OR}_{\mathrm{adj}} 2.83,95 \% \mathrm{CI} 2.25-3.55\right)$. Thus, our findings of male workers may not be valid for female workers.

\section{Concluding remarks}

Occupational exposure to HAV and cold environment increased the risk for WF compared to working in a warmer climate. The results underscore the need to keep exposure to HAV at workplaces as low as possible especially in cold climates.

\section{Acknowledgements}

The financial support of the Swedish AFA Insurance (Project 2008-0125) is gratefully acknowledged.

\section{References}

1. Bovenzi M. Exposure-response relationship in the hand-arm vibration syndrome: an overview of current epidemiology research. Int Arch Occup Environ Health. 1998;71:509-19.

2. Ashe W, Cook W, Old J. Raynaud's phenomenon of occupational origin. Arch Environ Health. 1962;5:333-43.

3. Futatsuka M, Inaoka T, Ohtsuka R, Sakurai T, Moji K, Igarashi $\mathrm{T}$. Hand-arm vibration in tropical rain forestry workers. Cent Eur J Public Health. 1995;3 suppl:90-2.

4. Yamamoto H, Zheng KC, Ariizumi M. A study of the handarm vibration syndrome in Okinawa, a subtropical area of Japan. Ind Health. 2002;40:59-62.

5. Yu ZS, Chao H, Qiao DS, Ye YH. Epidemiologic survey of vibration syndrome among riveters, chippers and grinders in the railroad system of the People's Republic of China. Scand J Work Environ Health. 1986;12(4):289-92

6. Torén K, Bergdahl IA, Nilsson T, Järvholm B. Occupational exposure to particulate air pollution and mortality due to ischaemic heart disease and cerebrovascular disease. Occup Environ Med. 2007;64:515-9.

7. Purdue MP, Järvholm B, Bergdahl IA, Hayes RB, Baris D. Occupational exposures and head and neck cancers among Swedish construction workers. Scand J Work Environ Health. 2006;32(4):270-5.

8. Bygghälsan. Miljöbeskrivning av sysselsättningar inom byggbranschen [Environmental descriptions of occupations within the construction industry]. Stockholm: Bygghälsan; 1977.

9. Statistics Sweden. Statistical Yearbook of Sweden 2009 Environment and weather. Stockholm: Statistics Sweden; 2009.

10. Harada N, Iwamoto M, Laskar MS, Hirosawa I, Nakamoto $\mathrm{M}$, Shirono S, et al. Effect of room temperature, seasonal condition and food intake on finger skin temperature during cold exposure test for diagnosing hand-arm vibration syndrome. Ind Health. 1998;36:166-70.

11. Miyashita K, Shiomi S, Itoh N, Kasamatsu T, Iwata H. Epidemiological study of vibration syndrome in response to 
total hand-tool operating time. Br J Ind Med. 1983;40:92-8.

12. Scheffer M, Dupuis H. Effects of combined hand-arm vibration and cold skin temperature. Int Arch Occup Environ Health. 1989;61:375-8.

13. Cherniack M, Clive J, Seidner A. Vibration exposure, smoking, and vascular dysfunction. Occup Environ Med. 2000;57:341-7.

14. Ekenvall L, Lindblad LE Effect of tobacco use on vibration white finger disease. J Occup Med. 1989;31:13-6.

15. Petersen, R., Andersen M, Mikkelsen S, Levin Nielsen S. Prognosis of vibration induced white finger: a follow up study. Occup Environ Med. 1995;52:110-5.

16. Gemne G. Pathophysiology of white fingers in workers using hand-held vibrating tools. Nagoya J Med Sci. 1994;57 suppl:87-97.
17. Lidström I-M (ed). Informationsdag 1978 - Vibrationers inverkan på människan [Information day 1978 - The vibrations influence of vibration on humans]. Stockholm: IVA, Report $147 ; 1979$.

18. European Council. Directive 2002/44/Ec of the European Parliament and of the Council of 25 June 2002 on the minimum health and safety requirements regarding the exposure of workers to the risks arising from physical agents (vibration) (sixteenth individual Directive within the meaning of Article 16(1) of Directive 89/391/EEC) [Internet]. Off J Eur Communities. 2002;L173:13-19 [cited 17 June 2010]. Available from: http://eur-lex.europa.eu/LexUriServ/ LexUriServ.do?uri=OJ:L:2002:177:0013:0019:EN:PDF

Received for publication: 2 March 2010 